\title{
Examination of Trait Anxiety States of University Students Doing Sports in Team and Individually in Terms of Some Variables
}

\author{
Serkan Zengin \\ Correspondence: Serkan Zengin, Ağrı İbrahim Cecen University, School of Physical Education and Sports, Ağr1, \\ Turkey.
}

Received: June 17, 2019

doi:10.11114/jets.v7i8.4324
Accepted: July 24, 2019 Online Published: July 26, 2019

URL: https://doi.org/10.11114/jets.v7i8.4324

\begin{abstract}
Research has been conducted for the students studying at Akdeniz University Faculty of Sports Sciences. In the research, it was aimed to investigate the trait anxiety states of students studying at Akdeniz University Faculty of Sports Sciences and a survey model was used in the study. This study is consisted of two parts; there are 6 items in determination of demographical variables in the first part. "Trait Anxiety Inventory" Scale consisting of 20 questions developed by Spielberger was used in the second part. Likert type four-point was used in the scale items given in the second and third parts (showing the statements "Almost Always", "Sometimes", "Usually", "Almost Never"). Once the comparison of trait anxiety levels by the age groups is examined among the results of the study, it is seen that trait anxiety levels of participants differ at a statistically significant level by the age groups $(\mathrm{p}<0,05)$. It was concluded that the trait anxiety level of the participants in the age group of 20-21 and age group of 22-23 is significantly higher than the participants in the age group of $23+(\mathrm{P}<0,05)$. In conclusion, it is considered that those who do individual sports feel more anxiety states since the responsibility only belongs to themselves. Trainings minimizing the anxiety should be further offered to the individuals doing such sports. Individual team athletes who are at national team level may be more supported.
\end{abstract}

Keywords: trait anxiety, team sports, individual sports, sports sciences

\section{Introduction}

It is seen that excellence in the physical capacity is not adequate alone in bringing the sportive performance to high-levels in our present day's sports. Athlete has a psychological capacity in another aspect and it should be cared at least as much as the physical aspect. This accounts for the inability of athletes experiencing emotional changes to reach the expected success although they are physically ready (Tavacioğlu, 1999; Erkan, 1998; Akarçeşme, 2004). Once it is considered that many high-level athletes have excellent abilities in sense of psychological capacities such as being motivated, managing the anxieties, concentrating and setting objectives as well as their physical and physiological capacities (Koç, 2004), the fact stating that the psychological dimension should not be ignored in increasing the sportive performance, emerges. There are many psychological facts affecting the performance in the sports. One of those that are the most important is anxiety.

While the anxiety is defined as "a state of waiting which distresses and bothers the person about the future, an excitement state mixed with feeling of insecurity" (Öncül, 2000; Coşkun ve Günbey, 2009), it is also defined as "a feeling experienced before any hazard opportunity originating from external world or any case perceived and interpreted by the person hazardous" (Alisinanoğlu and Ulutaş, 2000). In case of anxiety, the individual feels himself/herself in an alarm state and as if something would happen and is filled with apprehension (Nar, 2005). The state of anxiety, one of the most important reasons, that is a subconscious memory (Morgan, 2000) related with a scaring warning points out a picture with physical symptoms such as tremor, sweating, palpitation and hypertension (Beck and Emery, 2006). The anxiety is divided into two parts as state anxiety and trait anxiety. The state anxiety is defined as "a form of anxiety which originates from stress based on environmental conditions, is mainly based on logical reasons, could be understood by others and is generally based on the temporary state which any individual experiences" (Öner and Le Compte, 1998; Selya, 1998; Kuru, 2000). The state anxiety is the most important criterion in trying to understand the athlete. It is an important anxiety type in terms of athlete in the on-going competitions, before and after the competitions. It is related with the personality of the athlete (İkizler, 1993). The trait anxiety is defined as "the state in which state generating stress is perceived as hazardous or threatening and frequency and intensity of the state emotional reactions against these threats increase and gain continuity". It is also possible to describe the trait 
anxiety as chronic anxiety for its characteristics. This anxiety type that is not based on hazards directly coming from the environment, internally originates. It is a dissatisfaction and unhappiness feeling due to the fact that unharmful cases are perceived by the individual as hazardous and essence-threatening. It is seen that those whose such anxiety type level is high are injured and descend into desperation too easily (Canbaz, 2001).

Intensity and duration of such an anxiety type vary by the personality structure. A personality structure being inclined to anxiety affects the trait anxiety level (İkizler, 1993). The trait anxiety cannot be directly observed in behaviors of the individual. However, it may be utilized from intensity and frequency of the state anxiety reactions detected at different times and conditions (Öner and Le Compte, 1998). Importance of the anxiety level of the athletes in achieving the requested or expected performance is great.

The anxiety level may affect the competition result and performance negatively (Başer, 1998). As the anxiety level increases, the athlete goes away from exhibiting his/her abilities in giving the right decision. Athletes who are under excessive pressure may engage in some wrong movements. While the excessive anxiety makes the athletes forget some movements that they know by heart and perform in trainings repeatedly, they may lead to confusion in the emotions and cause them to make some negative movements (Gümüş, 2002). Each competition is of great importance for the athlete in social and economic aspects. No matter how excellent the physical characteristics an athlete has and how perfect he/she undergoes a training process in such an environment, the ability of dealing with the anxiety is a highly important criterion in succeeding. Psychological preparation should be different in compliance with the nature of sports branches.

\section{Material and Method}

Research has been conducted for the students studying at Akdeniz University Faculty of Sports Sciences. General screening model was used in the study. A total of 197 participants (Male=100, Female=97) with an average age of 22.03 were included in the study. This study is consisted of two parts; there are 6 items in determination of demographical variables in the first part. "Trait Anxiety Inventory" Scale consisting of 20 questions developed by Spielberger was used in the second part. Validity and reliability coefficient of Trait Anxiety Inventory Scale were .71-.84 and .87. Likert type four-point was used in the scale items given in the second and third parts (showing the statements "Almost Always", "Sometimes", "Usually", “Almost Never").

\section{Statistical Analysis}

SPSS 22.0 program was used for the analysis of data obtained. While Independent $T$ test was used in comparison of scale scores of the participants by gender and sports type they engage, One Way ANOVA analysis was used in comparison of scale scores by the age groups, sports ages, states of national team and monthly income states. SPSS 22.0 program was used for the analysis of data obtained. While Independent T test was used in comparison of scale scores of the participants by gender and sports type they engage, One Way ANOVA analysis was used in comparison of scale scores by the age groups, sports ages, states of national team and monthly income states.

\section{Findings}

Table 1. Frequency and Percentage Distributions of Demographical Information of Participants

\begin{tabular}{|c|c|c|c|}
\hline Variable & Sub-variable & $\mathbf{f}$ & $\%$ \\
\hline \multirow{2}{*}{ Gender } & Male & 100 & 50,8 \\
\hline & Female & 97 & 49,2 \\
\hline \multirow{4}{*}{ Age group } & 18-19 years old & 24 & 12,2 \\
\hline & 20-21 years old & 60 & 30,5 \\
\hline & 22-23 years old & 60 & 30,5 \\
\hline & $23+$ years old & 53 & 26,9 \\
\hline \multirow{2}{*}{ Type of Sports } & Team & 115 & 58,4 \\
\hline & Individual & 82 & 41,6 \\
\hline \multirow{4}{*}{ Age of Sports } & $1-3$ years & 12 & 6,1 \\
\hline & 4-6 years & 35 & 17,8 \\
\hline & $7-9$ years & 59 & 29,9 \\
\hline & 9+ years & 91 & 46,2 \\
\hline \multirow{3}{*}{ State of National Team } & $\mathrm{A}$ & 30 & 15,2 \\
\hline & $\mathrm{B}$ & 165 & 83,8 \\
\hline & $\mathrm{C}$ & 2 & 1,0 \\
\hline \multirow{3}{*}{ Monthly Income State } & $1000-1500$ & 54 & 27,4 \\
\hline & $1500-3000$ & 69 & 35,0 \\
\hline & 3000 and above & 74 & 37,6 \\
\hline
\end{tabular}

$50,8 \%$ of the sampling group included into the study is consisted of male, $49,2 \%$ is consisted of females and $12,2 \%$ is in 
the group of $18-19$ years old, $30,5 \%$ in the group of 20-21 years old, 30,5\% in the group of 22-23 years old and 26,9\% in the group of 23- years old. 38,4\% of the participants engages in team sports, $41,6 \%$ engages in individual sports, $6,1 \%$ has been doing sports for 1-3 years, $17,8 \%$ has been doing sports for 4-6 years, $29,9 \%$ has been doing sports for 7-9 years, $46,2 \%$ has been doing sports for $9+$ years. $15,2 \%$ of the participants is A national, $83,8 \%$ is B national, $1 \%$ is $\mathrm{C}$ national. While $27,4 \%$ of the participants has a monthly income of 1000-1500 TRY, $25 \%$ has an income amounting to 1500-3000 TRY, 37,6\% has an income amounting to 3000 TRY and above.

Table 2. Descriptive Statistics for the Trait Anxiety Levels of Participants

\begin{tabular}{c|c|c}
\hline $\mathbf{N}$ & $\mathbf{X}$ & $\mathbf{S s}$ \\
\hline 197 & 41,75 & 8,739 \\
\hline
\end{tabular}

Once Table is examined, it is seen that the trait anxiety levels of participants are at intermediate level.

Table 3. Comparison of Trait Anxiety Levels of Participants by Gender

\begin{tabular}{c|c|c|c|c|c}
\hline Gender & $\mathbf{N}$ & $\mathbf{X}$ & $\mathbf{S s}$ & $\mathbf{t}$ & $\mathbf{p}$ \\
\hline Male & 100 & 40,76 & 8,726 & $-1,615$ & \multirow{2}{*}{, 108} \\
\hline Female & 97 & 42,76 & 8,679 & & \\
\hline
\end{tabular}

Once Table is examined, it is seen that the trait anxiety levels of participants do not differ at a statistically significant level by the gender $(\mathrm{p}>0,05)$.

Table 4. Comparison of Trait Anxiety Levels of Participants by Age Groups

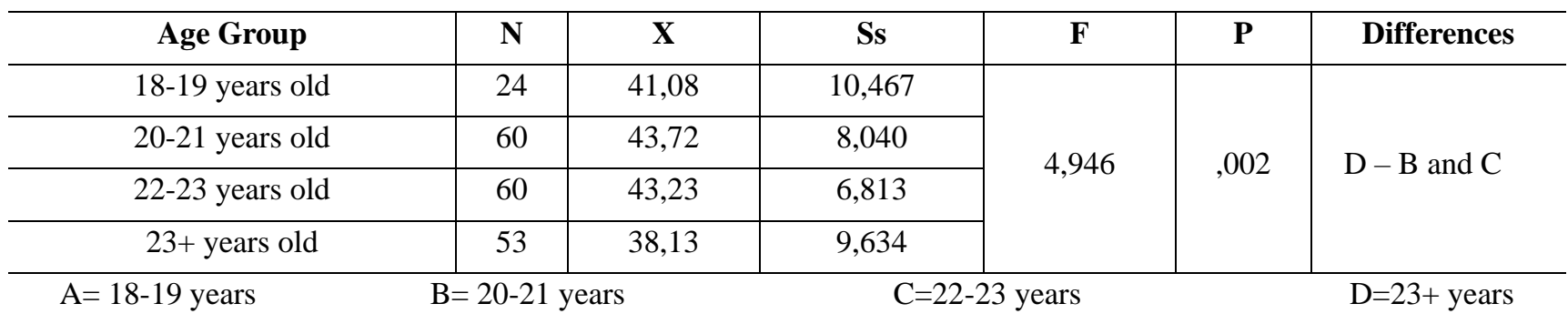

Once Table is examined, it is seen that the trait anxiety levels of participants differ at a statistically significant level by the age groups $(\mathrm{p}<0,05)$. The trait anxiety level of the participants in the age group of 20-21 and age group of 22-23 is significantly higher than the participants in the age group of $23+(\mathrm{P}<0,05)$.

Table 5. Comparison of Trait Anxiety Levels of Participants by Type of Sports They Engage

\begin{tabular}{c|c|c|c|c|c}
\hline Type of Sports & $\mathbf{N}$ & $\mathbf{X}$ & $\mathbf{S s}$ & $\mathbf{t}$ & $\mathbf{p}$ \\
\hline Team & 115 & 41,61 & 8,974 & \multirow{2}{*}{,- 261} & \multirow{2}{*}{, 794} \\
\hline Individual & 82 & 41,94 & 8,448 & \\
\hline
\end{tabular}

Once Table is examined, it is seen that the trait anxiety levels do not differ at a statistically significant level by the type of sports the participants engage ( $p>0,05)$.

\section{Discussion and Conclusion}

Once frequency and percentage distributions of participants included into our study for the demographical information given in Table 1 are examined, 50,8\% of the sampling group included into the study is consisted of male, $49,2 \%$ is consisted of females and $12,2 \%$ is in the group of $18-19$ years old, $30,5 \%$ in the group of $20-21$ years old, $30,5 \%$ in the group of 22-23 years old and $26,9 \%$ in the group of 23- years old. $38,4 \%$ of the participants engages in team sports, $41,6 \%$ engages in individual sports, $6,1 \%$ has been doing sports for $1-3$ years, $17,8 \%$ has been doing sports for $4-6$ years, $29,9 \%$ has been doing sports for 7-9 years, $46,2 \%$ has been doing sports for $9+$ years. $15,2 \%$ of the participants is A national, $83,8 \%$ is B national, $1 \%$ is $\mathrm{C}$ national. While $27,4 \%$ of the participants has a monthly income of $1000-1500 \mathrm{TRY}, 25 \%$ has an income amounting to $1500-3000$ TRY, $37,6 \%$ has an income amounting to 3000 TRY and above. Once the descriptive statistics for the trait anxiety levels of participants is examined in Table 2, it is seen that the trait anxiety levels of participants are at intermediate level. Once the comparison of trait anxiety levels of participants by the gender is examined in Table 3, it is seen that the trait anxiety levels of participants do not differ at a statistically significant level by the gender $(p>0,05)$. In another study conducted in 2008 , a significant correlation was not found between genders of students and trait anxiety level, that is a result which supports our result (Öztürk, 2008.). In the study conducted by named Examination of state anxiety and trait anxiety levels of athletes by some variables; totally 324 
athletes at 14 (years old) who do sports in basketball, volleyball, handball, taekwondo-do and wrestling branches; 132 females and 192 males, participated into the study and State Trait Anxiety Inventory (STAI) was used in the study (Başaran, and other 2009).

No significant difference was found between trait anxiety scores of female and male athletes in the research. According to this study's results; it can be said that genders of students do not create a difference over the trait anxiety levels. According to the results of Table 4, it is seen that the trait anxiety levels differ at a statistically significant level by the age groups of the participants as a result of the comparison of trait anxiety levels $(\mathrm{p}<0,05)$. The trait anxiety level of the participants in the age group of 20-21 and age group of 22-23 is significantly higher than the participants in the age group of 23+ $(\mathrm{P}<0,05)$. Although there were numerical differences between the trait anxiety means in terms of both age and gender of the athletes who are at 17-22 years old and above participated into another study conducted in 2010, no statistically difference was found (Civan and other 2010).

In relation to this finding, noted in his master's thesis that there is a significant difference between age variable in terms of trait anxiety scores (Civan 2001) concluded in the research performed on those who engage in taekwondo that low or high state and trait anxiety levels of athletes do not depend on the ages of subjects (Yücel 2003). The study performed shows similarity with the literature. Once the comparison of trait anxiety levels of participants is examined by the type of sports in Table 5, it is seen that the trait anxiety levels do not differ at a statistically significant level by the type of sports the participants engage ( $p>0,05)$.

Once sports branches were examined in terms of trait anxiety score in another research conducted in 2008, it is seen that trait anxiety score of taekwondo players is significantly higher than anxiety scores of basketball players in a multiple comparison performed. In comparison of other branches, a statistically significant difference was not detected in terms of trait anxiety scores (Başaran, 2008). Team sports have a different nature from the individual sports. It is stated that the anxiety intensity is higher in those who do individual sports compared with those who do team sports (Konter, 1998). By starting from these results, it is considered that those who do individual sports feel more anxiety states since the responsibility only belongs to themselves. Trainings minimizing the anxiety should be further offered to the individuals doing such sports. Individual team athletes who are at national team level may be more supported.

\section{References}

Alisinanoğlu, F., \& Ulutaş, İ. (2003). Investigation of the Relationship Between Anxiety Levels and Anxiety Levels of Children. Education and Science, 28(128), 65-71.

Aydemir, Ö., \& Koroglu, E. (2000). Clinical Scales Used in Psychiatry Dr. Ankara: Physicians Publication Association.

Başaran M. H. (2008.) Investigation of the Anxiety Levels of Athletes According to Some Variables.

Basaran, M. H., Tasgin, O., Sanioglu, A., \& Taskin A. K. (2009). Examination of state and trait anxiety levels in athletes according to some variables. Selçuk University Journal of the Institute of Social Sciences, 21, 533-542.

Beck, A. T., \& Emery, G. (2005). A Cognitive Perspective on Anxiety Disorders and Phobias. Trans. Contact Veysel directly Istanbul: Litera Publishing.

Canbaz, S. (2001). Evaluation of sociodemographic, working life characteristics and state-trait anxiety levels of apprentices attending Samsun Apprenticeship Training Center. Master Thesis, 19 Mayıs University, Samsun.

Civan, A., Arı, R., \& Görücü, Ö. M. (2010) Comparison of state and trait anxiety levels of individual and team athletes before and after the competition

Civan, A. (2001). Comparison of state and trait anxiety of individual and team athletes before and after the competition. Master Thesis, Selcuk University Institute of Health Sciences, Konya.

Gemini, C. (1993). Psychological Factors Affecting Success in Sports and Psychological Training. Unpublished PhD Thesis. MU Health Sciences Institute. Istanbul.

Kuru, E. (2000). Psychology in Sport. Ankara: G. Ü. Faculty of Communication Printing House.

Morgan, T. C. (2000). Introduction to Psychology. Trans. HU Department of Psychology. Ankara: H. Ü. Psychology Department Publications.

Nar, E. (2005). Understand me. 3rd Edition, Istanbul: Porte Culture Publishing.

Precursor, R. (2000). Dictionary of Education and Educational Sciences. Ankara: M.E.B. Publications.

Öner, N., \& Le Compte, A. (1983). Discontinuous State Continuous Anxiety Inventory Handbook. İstanbul: Boğaziçi University Publishing House.

Öner, N., \& Le Compte, A. (1998). Inventory of Discontinuous State Trait Anxiety. İstanbul: Boğaziçi University 
Publishing House.

Oshkun, Y., \& Gunbey, A. (2009). Relationship Between Perceived Anxiety Levels and Social Support Perceptions of Mothers with Handicapped Children. Ahi Evran University Kirsehir Faculty of Education Journal (Kefad), 10(1).

Ozturk A. (2008). Manisa Celal Bayar University School of Physical Education and Sports Teaching Program Students' Status and Continuous Anxiety Levels Relationship between Academic Achievement. Ozturk A. (2008)

Şahin, N. H., Batıgün, A. D., \& Uğurtaş, S. (2002). Brief Symptom Inventory (BSI): Validity, Reliability and Factor Structure of Adolescents. Turkish Journal of Psychiatry, 13(2).

Selya, H. (1998). Stress without distress. (Ed. Barbara Woods) Applying psychology to sport. Hodder \& Stoughton. 98-109.

Yucel, E. O. (2003). State anxiety and trait anxiety levels of taekwondo players and their effect on competition success. Master Thesis, Gazi University Institute of Health Sciences, Ankara.

\section{Copyrights}

Copyright for this article is retained by the author(s), with first publication rights granted to the journal.

This is an open-access article distributed under the terms and conditions of the Creative Commons Attribution license which permits unrestricted use, distribution, and reproduction in any medium, provided the original work is properly cited. 